\title{
SIMULASI PENEMPATAN TRANSFORMATOR PADA JARINGAN DISTRIBUSI BERDASARKAN JATUH TEGANGAN MENGGUNAKAN ETAP POWER STATION 12.6.0
}

\author{
Fajar Dwi Safitri ${ }^{1}$, Henry Ananta ${ }^{2}$ \\ ${ }^{1,2}$ Pendidikan Teknik Elektro Fakultas Teknik Universitas Negeri Semarang \\ email : fajardwisafitri98@gmail.com
}

\begin{abstract}
Channeling electrical energy from the power plant to the load experiences a voltage drop. This happens because the number of PLN consumers are increasing every year that gives impact on increasing network length and the burden that must be supplied. This study aims to analyze the voltage drop on the KLSO6 feeder. To do these calculations ETAP Power Station12.6.0 software is used using the Newton-Raphson method. The KLS 06 Feeder distribution network is included in the working area of PT PLN (Persero) UP3 Semarang. In the 3 phase $50 \mathrm{kV}$ distribution transformer with KLSO6-110 number, the load exceeds the standard limits. So that the Bus24 experienced a voltage drop of 3.75\%. Based on SPLN 72: 1987 the maximum allowable voltage drop in JTR is $4 \%$.. To maintain the quality of the voltage and anticipate the occurrence of falling voltage is greater due to the burden of load, it is necessary to perform the insert of a connected transformer with the transformer KLSO6-110. From the analysis of the result after the transformer is obtained the value of falling voltage at Bus 24 is reduced by $1.75 \%$ so the value becomes $2 \%$.
\end{abstract}

Keywords: Distribution Network, Transformer, Voltage Drop

\begin{abstract}
ABSTRAK
Penyaluran energi listrik dari pusat pembangkit sampai ke beban mengalami jatuh tegangan. Hal ini terjadi karena jumlah konsumen PLN tiap tahunnya meningkat sehingga mengakibatkan jaringan bertambah panjang dan beban yang harus disuplai. Penelitian ini bertujuan untuk menganalisis jatuh tegangan pada Penyulang KLS06. Untuk melakukan perhitungan tersebut digunakan software ETAP Power Station 12.6.0 dengan menggunakan metode Newton-Raphson. Jaringan distribusi Penyulang KLS 06 termasuk wilayah kerja PT PLN (Persero) ULP Semarang. Pada transformator distribusi 3 fasa 50 kV Penyulang KLS06-110 mengalami pembebanan yang melebihi batas standar. Sehingga pada Bus24 mengalami jatuh tegangan sebesar 3,75\%. Berdasarkan SPLN 72: 1987 batas maksimum jatuh tegangan yang diijinkan pada JTR yaitu 4\%. Untuk mempertahankan kualitas tegangan dan mengantisipasi terjadinya jatuh tegangan yang lebih besar akibat pertambahan beban, maka perlu dilakukan sisip transformator secara paralel dengan transformator KLS06-110. Dari hasil analisis setelah dilakukan sisip transformator didapat nilai jatuh tegangan pada Bus24 berkurang $1,75 \%$ sehingga nilainya menjadi $2 \%$.
\end{abstract}

Kata kunci: Jaringan Distribusi, Transformator, Jatuh Tegangan

\section{PENDAHULUAN}

Pertumbuhan penduduk dan pembangunan industri-industri di Indonesia semakin pesat. Begitu pula dengan kebutuhan akan energi listrik yang tiap tahunnya ikut meningkat. Supaya energi listrik yang dibangkitkan bisa sampai ke pelanggan, maka perlu disalurkan melalui sistem tenaga listrik. Sistem tenaga listrik ini terdiri dari pusat pembangkitan, saluran transmisi, dan saluran distribusi. Pada penyalurannya dari pusat pembangkitan menuju ke beban melalui suatu jaringan yang sangat jauh. Seiring dengan bertambahnya waktu dan pertumbuhan ekonomi di Indonesa, jumlah konsumen yang 
tersambung ke jaringan PLN juga semakin bertambah. Sehingga kondisi jaringan listrik yang terpasang pun juga turut berubah menjadi lebih panjang. Jarak dari transformator distribusi menuju ke beban jadi lebih jauh. Sehingga penempatan transformator sudah tidak tepat lagi.

Kasus jatuh tegangan sering sekali terjadi pada sistem jaringan listrik di berbagai daerah karena terjadinya penambahan beban yang tersambung. Untuk memberikan pelayanan yang baik dan agar tidak menimbulkan kerugian pada konsumen, Perusahaan Listrik Negara (PLN) harus menjaga kualitas tegangan pada jaringan. Oleh karena itu perlu dilakukan upaya-upaya agar jaringan distribusi selalu dalam kondisi baik.

Adapun upaya yang dapat dilakukan untuk memperbaiki profil tegangan pada jaringan distribusi yaitu pemasangan transformator baru (sisip transformator). Pada penelitian ini dilakukan perhitungan dan analisis jatuh tegangan serta analisis efektifitas penempatan transformator pada penyulang Kalisari (KLS) 06 sebagai upaya untuk perbaikan jatuh tegangan pada jaringan. Selain itu dalam penelitian ini juga disimulasikan menggunakan aplikasi ETAP 12.6.0 untuk memastikan tingkat efektifitas dari perencanaan perbaikan tegangan tersebut.

Suatu sistem tenaga listrik terdiri dari tiga bagian utama yaitu pusat pembangkit listrik, saluran transmisi, dan sistem distribusi. Pada jaringan distribusi terbagi dalam dua bagian yaitu Jaringan Tegangan Menengah dan Jarinngan Tegangan Rendah. Jaringan Tegangan Menengah (JTM) menyuplai konsumen pada daerah industri berukuran menengah, daerah perumahan kota besar dan daerah pedesaan dari trafo gardu induk, sedangkan tegangan rendah biasanya dipergunakan untuk mensuplai perumahan dan daerah industri ringan di kota-kota dan dan pedesaan dari trafo-trafo distribusi (Daryanto, 2002: 26).
Transformator yaitu suatu alat yang diguanakan untuk menaikkan atau menurunkan tegangangan. Menurut Salman (2017), kriteriakriteria transformator distribusi yang sering digunakan, yaitu transformator distribusi umumnya digunakan adalah transformator Step Down $20 \mathrm{KV} / 400$. Tegangan fasa ke fasa jaringan rendah adalah $380 \mathrm{~V}$. Karena terjadi drop tegangan, maka pada rak tegangan rendah dibuat menjadi $400 \mathrm{~V}$ agar tegangan pada ujung penerima tidak lebih kecil dari $380 \mathrm{~V}$. Transformator distribusi dapat berfasa tunggal atau tiga fasa dan kapasitasnya kira-kira $5 \mathrm{kVA}$. Impedansi transformator distribusi pada umumnya sangat rendah, kira-kira $2 \%$ untuk unit-unit yang kurang dari dari 50kVA dan sampai $4 \%$ untuk unit-unit yang lebih besar dari $100 \mathrm{KVA}$.

Salah satu komponen utama dalam saluran distribusi yaitu penghantar. Jenis penghantar yang digunakan dalam sistem distribusi yaitu kawat dan kabel. Jenis penghantar kawat yang sering digunakan yaitu All Alumunium Conductor (AAC) dan All Alumunium Alloy Conductor (AAAC). Sedangkan penghantar kabel yang sering dipakai dalam jaringan distribusi PLN yaitu kabel AAAC-S dan XLPE.

Tabel 1. Konstanta Jaringan Kawat Penghantar AAAC Menurut SPLN 64 Tahun 1985

\begin{tabular}{ccc}
\hline $\begin{array}{c}\text { Luas } \\
\text { Penampang } \\
\left(\mathbf{m m}^{2}\right)\end{array}$ & $\begin{array}{c}\text { Impedansi } \\
(\mathbf{O h m} / \mathbf{K m s})\end{array}$ & $\begin{array}{c}\text { KHA } \\
(\mathbf{A})\end{array}$ \\
\hline AAAC 240 & $0,1344+\mathrm{j} 0,3158$ & 585 \\
AAAC 150 & $0,2162+\mathrm{j} 0,3305$ & 425 \\
AAAC 70 & $0,4608+\mathrm{j} 0,3572$ & 155 \\
AAAC 50 & $0,6452+\mathrm{j} 0,3678$ & 210 \\
\hline
\end{tabular}

Daya yang dibangkitkan sebuah perangkat listrik sebanding dengan besarnya arus yang mengalir melewatinya. Daya juga sebanding dengan tegangan yang menggerakkan arus tersebut. Semakin besar arus dan semakin besar gaya gerak listriknya, semakin besar pulalah daya yang dihasilkan. Daya listrik dibedakan menjadi tiga yaitu: 1) 
Daya Semu (S), merupakan daya keseluruhan yang dikeluarkan, dan juga kapasitor generator. Satuannya yaitu kVA (kilovolt ampere) atau MVA (megavolt ampere), 2) Daya Nyata (P) yang digunakan untuk menggerakkan atau menyalakan peralatan-peralatan listik seperti seterika, motor listrik, kulkas, dan lain-lain, 3) Daya Reaktif, merupakan daya yang tidak bisa digunakan akibat pengaruh harga reaktansi dan beban. Faktor daya adalah perbandingan antara daya nyata dan daya semu.

Nilai faktor daya dalam suatu saluran mempengaruhi besarnya arus yang mengalir pada saluran tersebut. Nilainya yaitu antara 0 sampai dengan 1. Terlalu rendah nilai faktor daya dapat mengakibatkan rugi yang sangat besar pada saluran.

Jatuh tegangan adalah selisih antara tegangan pada pangkal pengiriman dengan tegangan pada ujung penerimaan tenaga listrik. Salah satu penyebab terjadinya jatuh tegangan yaitu bertambahanya beban atau konsumen yang tersambung.

Menurut Abrar Tanjung (2014:164), terdapat dua komponen yang mempengaruhi terjadiya penurunan tegangan yaitu:

a. $I \times R_{s}$ yaitu rugi-rugi tegangan yang diakibatkan oleh tahanan saluran

b. $\mathrm{I} \times \mathrm{X}_{1}$ yatiu rugi-rugi tegangan yang diakibatkan oleh reaktansi induktif saluran.

Sehingga besarnya jatuh tegangan dapat dinyatakan sebagai berikut:

$$
\begin{aligned}
& \Delta V=I \cdot R \cdot \cos \varphi+I \cdot X \cdot \sin \varphi \\
& \Delta V=I \times Z
\end{aligned}
$$

Untuk menghitung besarnya hambatan (R) digunakan rumus:

$$
R=\frac{\rho \times l}{A}
$$

Keterangan:

$$
\begin{array}{ll}
\Delta V & : \text { Jatuh tegangan (volt) } \\
\mathrm{I} & : \text { Arus yang mengalir (ampere) } \\
\mathrm{R} & : \text { Tahanan saluran (ohm) } \\
\mathrm{X} & : \text { Reaktansi (Ohm) } \\
\varphi & : \text { Sudut dari faktor daya beban }
\end{array}
$$

Z : Impedansi saluran

$\rho \quad$ : tahanan jenis penghantar $\left(\mathrm{mm}^{2} / \mathrm{m}\right)$

Berdasarkan SPLN 72: 1987 batas maksimum drop tegangan yang diijinkan adalah sebagai berikut:

a. Drop tegangan pada Jaringan Tegangan Menengah $=5 \%$

b. Drop tegangan pada trafo $=3 \%$

c. Drop tegangan pada Jaringan Tegangan Rendah $=4 \%$

d. Drop tegangan pada Saluran Pelayanan $=$ $1 \%$

Untuk mrnghitung presentase jatuh tegangan yang terjadi pada jaringan digunakan rumus:

$$
\Delta V=\frac{V_{s}-V_{r}}{V_{S}} \times 100 \%
$$

Keterangan:

$\mathrm{Vs}=$ tegangan pada pangkal pengiriman

$\mathrm{Vr}=$ tegangan pada ujung penerimaan

ETAP (Electrical Transient Analysis Program) merupakan suatu perangkat lunak (software) yang mendukung sistem tenaga listrik. Aplikasi ini dapat digunakan untuk membuat proyek sistem tenaga listrik dalam bentuk diagram satu garis (one line diagram) dan jalur sistem pentanahan untuk berbagai bentuk analisis, antara lain: aliran daya, hubung singkat, starting motor, transient stability, koordinasi relay proteksi, sistem harmonisa dan lain sebagainya (Hayusman, Hidayat \& Saleh, 2017: 8).

Software ETAP Power Station dilengkapi dengan fasilitas Library yang data-datanya dapat diubah sesuai dengan yang sebenarnya pada komponen-komponen yang digunakan. Selain itu untuk mendukung dalam pembuatan simulasi aplikasi ini dilengkapi dengan banyak tool yang melambangkan suatu komponen yang digunakan dalam jaringan yang akan dianalisa.

Analisis aliran daya ini bertujuan untuk mengetahui karakteristik aliran daya yang berupa pengaruh dari variasi beban dan rugirugi transmisi pada aliran daya dan juga mempelajari adanya jatuh tegangan di sisi 
beban (Multa \& Aridani, 2013). Menurut Sulasno (1993), terdapat dua metode yang dapat digunakan untuk perhitungan aliran daya yaitu Metode Gauss-Seidel dan Metode NewtonRaphson. Masing-masing metode memiliki kelebihaan dan kelemahan.

Kelebihan yang dimiliki dari metode Gauss-Seidel yaitu:

a. Pemrograman dan perhitungannya relative lebuh mudah.

b. Hanya butuh sedikit nilai masukan.

c. Waktu tiap iterasi singkat.

d. Metode ini cocok digunakan pada sistem tenaga listrik yang jaringannya sedikit.

Sedangkan kelemahan dari metode GaussSeidel ini yaitu:

a. Kecepatan perhitungannya sedikit lebih lambat

b. Tidak cocok untuk sistem radial karena tidak dapat menvapai konvergen.

c. Semakin banyak simpul maka akan semakin banyak pula iterasi yang diperlukan. Julah iterasi juga akan berubah ketika bus referensinya diganti dengan bus lain.

d. Tidak cocok untuk sistem jaringan yang banyak.

\section{Metode Newton-Raphson} merupakan hasil perkembangan dari metode Gauss-Seidel yang lebih disempurnakan. Metode N-R dianggap lebih efektif dan menguntungkan untuk sistem jaringan yang lebih besar. Selain itu juga dapat menutup kelemahan dari metode Gauss-Seidel yaitu tingkat ketelitiaannya lebih baik, kemudian membutuhkan jumlah iterasi yang lebih sedikit dan mampu menghitung dengan waktu yang lebuh cepat. Menurut Martínez-Molina dan Ledezma (2016), metode N-R telah berhasil membuktikan dalam sebagian besar kasus bahwa memiliki karakteristik konvergensi yang kuat.

Selain dua metode di atas, dalam ETAP untuk melakukan kalkulasi aliran daya ada satu lagi metode tambahan yaitu metode Fast Decoupled. Kelebihan serta kelemahan dari metode ini yaitu baik untuk sistem jaringan radian dan jaringan yang panjang serta cepat dalam penghitungan akan tetapi memiliki tingkat presisi yang kurang.

\section{METODE}

Teknik analisis data yang digunakan dalam penelitian ini yaitu statistik deskriptif. Teknik ini digunakan untuk menganalisis data yang telah terkumpul tanpa berrmaksud membuat kesimpulan yang berlaku untuk umum.

Penelitian ini dilaksanakan pada bulan Agustus 2019 di PT PLN (Persero) UP3 Semarang. Obyek penelitian ini yaitu Penyulang Kalisari (KLS) 06. Supaya tujuan penelitian dapat tercapai sesuai dengan yang diharapkan, diperlukan perencanaan prosedur penelitian terlebih dahulu. Berikut ini adalah flowchart prosedur penelitian.

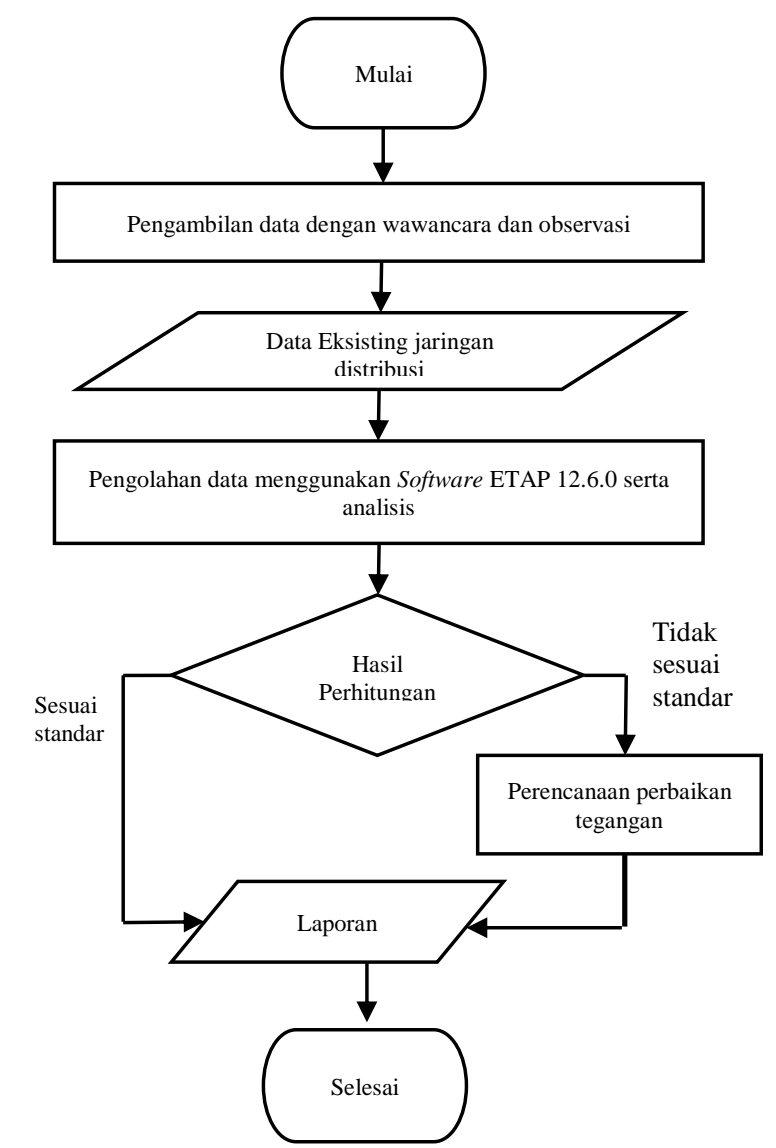

Gambar 1. Flowchart Prosedur Penelitian 
Aplikasi yang digunakan untuk menghitung dan menganalisis data-data yang sebelumnya telah terkumpul yaitu dengan menggunakan software ETAP 12.6.0 untuk mengetahui jatuh tegangan yang terjadi pada sepanjang jaringan masih memenuhi standar toleransi atau tidak.

Perencanaan perbaikan tegangan dilakukan ketika dalam jaringan tersebut terjadi jatuh tegangan melebihi standar yang diijinkan. Untuk mengurangi rugi-rugi daya dan jatuh tegangan pada jaringan distribusi tersebut dilakukan penggeseran transformator distribusi.

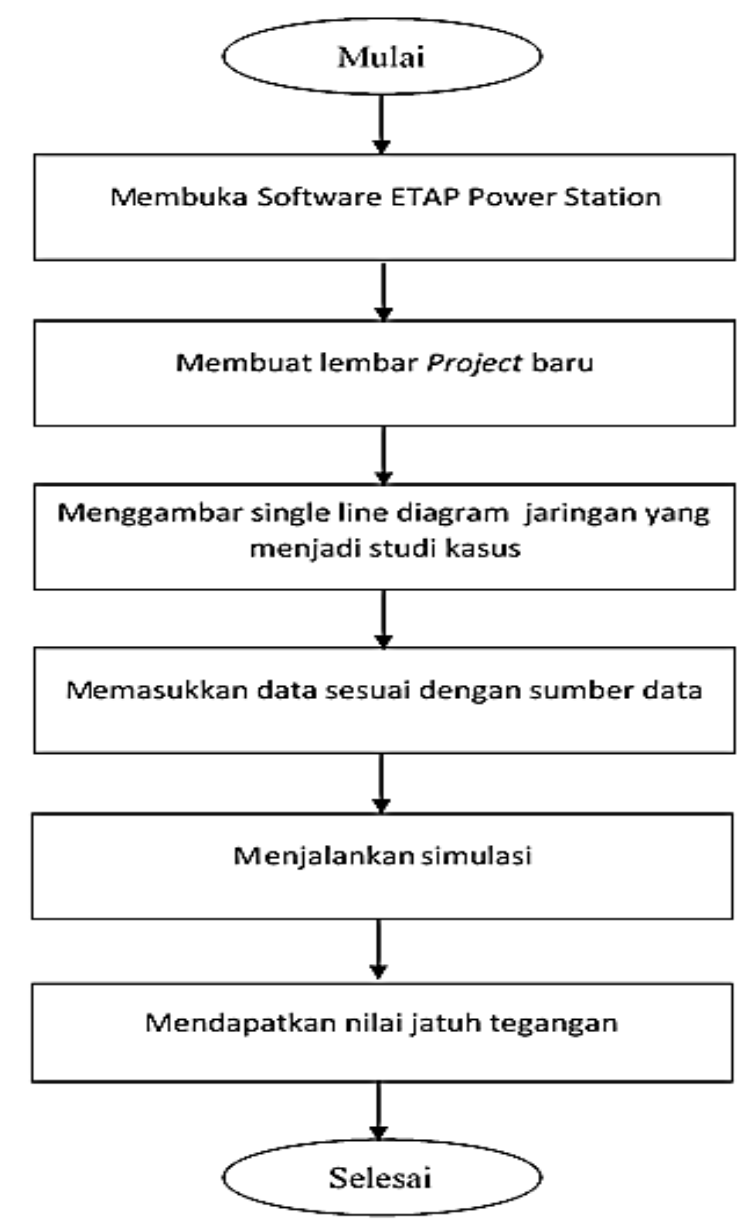

Gambar 2. Flowchart Simulasi ETAP Power Station

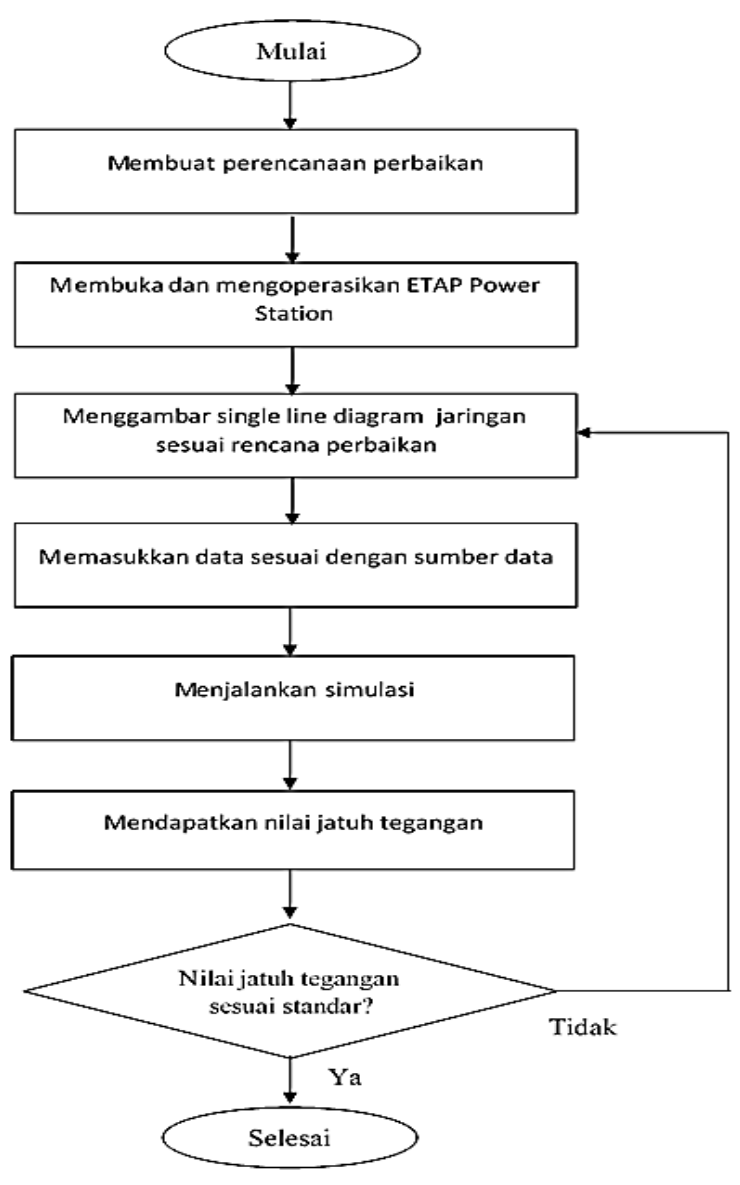

Gambar 3. Flowchart Perencanaan Perbaikan

\section{HASIL DAN PEMBAHASAN}

Dalam menganalisis tata letak transformator, perlu diketahui besarnya nilai jatuh tegangan yang terjadi pada saluran distribusi pada penyulang KLS 06. Untuk melakukan analisis terebut diperlukan data-data sebagai masukannya diantaranya yaitu: data transformator utama, data trafo utama, kapasitas dan beban trafo, luas penampang dan panjang kabel yang digunakan, serta Single Line Diagram Penyulang Kalisari 06 dapat dilihat pada Tabel 1.

Tabel 1. Data Transformator

\begin{tabular}{ccccc}
\hline $\begin{array}{c}\text { Gardu } \\
\text { Induk }\end{array}$ & \multicolumn{4}{c}{ Data Transformator } \\
\cline { 2 - 5 } & Unit & $\begin{array}{c}\text { Daya } \\
\text { (MVA) }\end{array}$ & $\begin{array}{c}\text { Teg. Sec } \\
(\mathbf{k V})\end{array}$ & $\begin{array}{c}\text { In } \\
(\mathbf{A})\end{array}$ \\
\hline Kalisari & I & 60 & 20 & 1732 \\
\hline
\end{tabular}


Pada Sistem Distribusi $20 \mathrm{kV}$ Wilayah Kerja PT PLN (Persero) ULP Semarang Barat terdapat dua trafo utama yang dipakai yaitu Trafo merk Xian dengan kapasitas 60 MVA yang digunakan untuk menyuplai 12 feeder. Untuk Feeder (Penyulang) Kalisari 06 disuplai oleh transformator 1.

Penghantar yang digunakan pada saluran distribusi Pengulang Kalisari 06 yaitu AAAC dengan luas penampang $240 \mathrm{~mm}^{2}$ dan $150 \mathrm{~mm}^{2}$ dengan impedansi sebesar $R_{1}=0,1344 \mathrm{ohm} / \mathrm{km}$, $\mathrm{j} \mathrm{X}_{1}=0,3158 \mathrm{ohm} / \mathrm{km}, \mathrm{R}_{0}=0,3631 \mathrm{ohm} / \mathrm{km}$ dan $\mathrm{j} \mathrm{X}_{0}=1,6180$. Data saluran antar gardu distribusi tiga fasa yang digunakan pada Penyulang Kalisari 06 dan data beban yang tersambung ditunjukan pada Tabel 2 dan 3.

Tabel 2. Data Saluran Penyulang Kalisari 06

\begin{tabular}{ccc}
\hline No & ID & Jarak $(\mathbf{k m})$ \\
\hline 1 & Cable1 & 2,00 \\
2 & Cable2 & 0,05 \\
3 & Cable3 & 0,75 \\
4 & Cable4 & 0,65 \\
5 & Cable5 & 0,60 \\
6 & Cable6 & 0,15 \\
7 & Cable7 & 0,15 \\
8 & Cable8 & 0,15 \\
9 & Cable9 & 0,55 \\
10 & Cable10 & 0,20 \\
11 & Cable11 & 0,60 \\
12 & Cable12 & 0,85 \\
13 & Cable13 & 0,35 \\
14 & Cable14 & 0,95 \\
15 & Cable15 & 0,40 \\
16 & Cable16 & 0,15 \\
17 & Cable17 & 0,25 \\
18 & Cable18 & 0,15 \\
\hline
\end{tabular}

Sebelum melakukan perhitungan jatuh tegangan pada jaringan distribusi Kalisari 06 hal pertama yang harus dilakukan yaitu menggambar Single Line Diagram (SLD). Metode yang digunakan dalam simulasi ini yaitu metode Newton Raphson karena jika dibandingkan dengan metode Gauss-Siedel tingkat ketelitiaannya lebih baik, kemudian membutuhkan jumlah iterasi yang lebih sedikit dan mampu menghitung dengan waktu yang lebih cepat.

Pada hasil simulasi menggunakan ETAP Power Station seperti yang ditunjukkan oleh Gambar 4 terdapat komponen yang berwarna merah, ungu, dan hitam. Arti dari masingmasing warna yaitu merah menunjukkan tegangan pada komponen tersebut dalam kondisi kritis yang menandakan harus dilakukan evaluasi, komponen berwarna ungu artinya tegangan pada komponen tersebut dalam kondisi marginal yaitu melebihi kapasitas akan tetapi masih dalam batas toleransi. Sedangkan untuk komponen yang berwarna hitam artinya tegangan pada komponen tersebut masih dalam kategori aman atau sesuai standar. 
Tabel 3. Data Beban di Penyulang Kalisari 06

\begin{tabular}{|c|c|c|c|c|c|c|c|}
\hline No & Nomor Gardu & $\begin{array}{c}\text { Kapasitas } \\
\text { Daya } \\
\text { (KVA) }\end{array}$ & $\mathbf{R}$ & $\begin{array}{c}\text { Beban } \\
\text { S }\end{array}$ & $\mathbf{T}$ & $\begin{array}{c}\text { Beban } \\
\text { Riil } \\
(\mathbf{k V A})\end{array}$ & $\begin{array}{c}\text { Presentase } \\
\text { Pembebana } \\
\text { n } \\
(\%)\end{array}$ \\
\hline 1 & KLS 06-40\S01 & 50 & 28 & 16,9 & 27,4 & 15,9 & 31,8 \\
\hline 2 & KLS 06-55 & 100 & 72,8 & 59,1 & 50,2 & 40,1 & 40,1 \\
\hline 3 & KLS 06-67\B03 & 100 & 21.1 & 21.5 & 42.4 & 18,7 & 18,7 \\
\hline 4 & KLS 06-79 & 100 & 6.3 & 18.9 & 13.2 & 8,45 & 8.45 \\
\hline 5 & KLS 06-82\T03 & 160 & 108 & 73 & 110 & 64,02 & 40,01 \\
\hline 6 & KLS 06-82\T07 & 100 & 4.5 & 17.2 & 10.3 & 7,04 & 7.04 \\
\hline 7 & KLS 06-82\T19 & 100 & 58,8 & 127,7 & 36,2 & 48,99 & 48,99 \\
\hline 8 & KLS 06-93B & 200 & 73.1 & 100 & 58,1 & 50,86 & 25,43 \\
\hline 9 & KLS 06-93D & 200 & 18.2 & 51.4 & 39 & 23,89 & 11.95 \\
\hline 10 & KLS 06-110 & 50 & 75,4 & 69,1 & 67,7 & 46,7 & 93,4 \\
\hline 11 & KLS 06-117 & 100 & 19.1 & 26.7 & 6.7 & 11,55 & 11,55 \\
\hline 12 & KLS 06-136 & 50 & 20.3 & 11.1 & 15.8 & 10,38 & 20,76 \\
\hline 13 & KLS 06-144 & 100 & 30 & 65.6 & 89.3 & 40,68 & 40.68 \\
\hline 14 & KLS 06-147\B05 & 50 & 6.1 & 23.1 & 16.3 & 10,01 & 20,02 \\
\hline 15 & KLS 06-150 & 50 & 25,6 & 54,9 & 14,8 & 20,97 & 41,94 \\
\hline
\end{tabular}

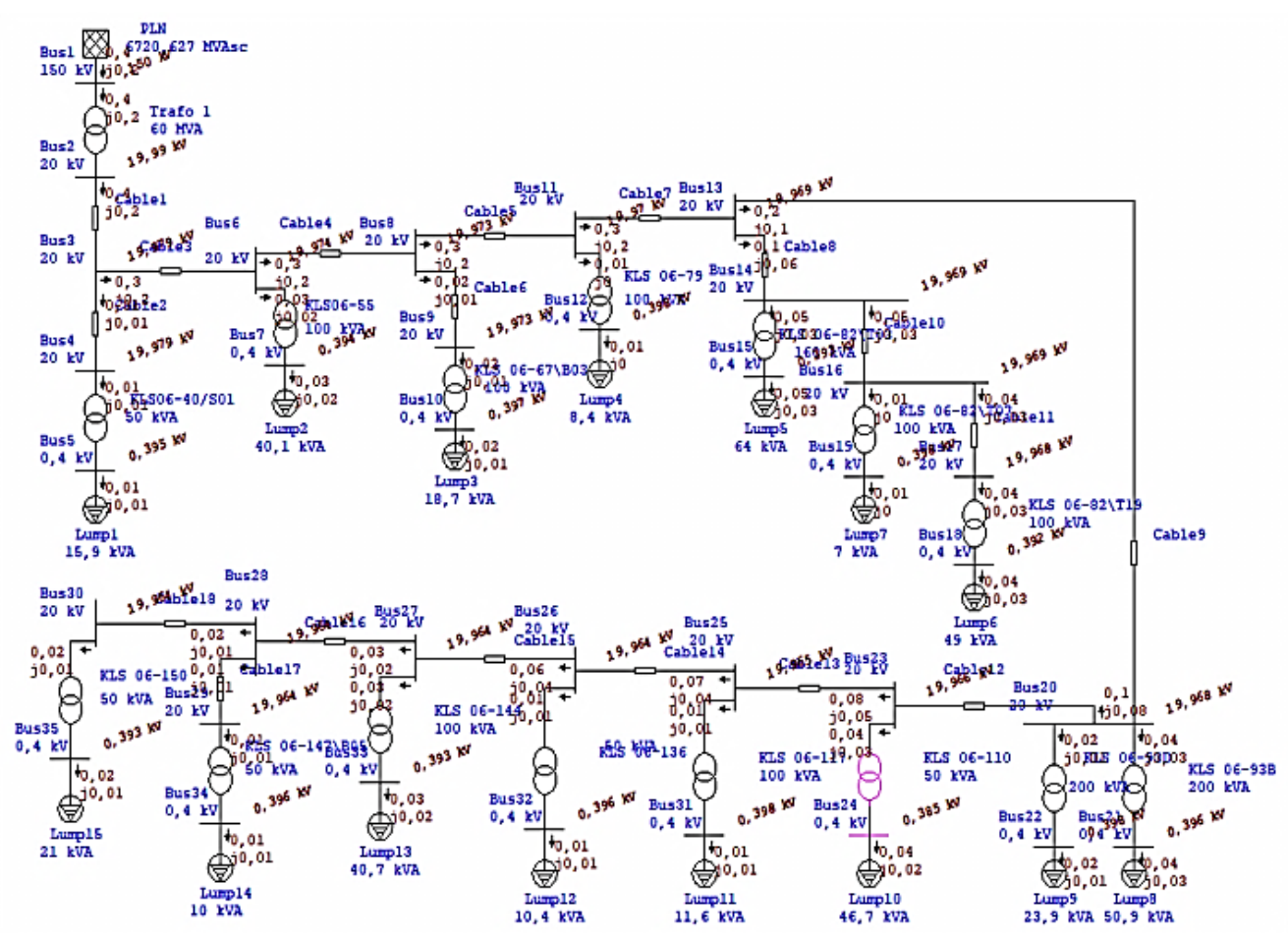

Gambar 4. Hasil Simulasi Jaringan Eksisting Kalisari 06 Menggunakan ETAP Power Station 
Perhitungan jatuh tegangan berikut ini merupakan perhitungan presentase tegangan kirim dan tegangan yang diterima. Besarnya tegangan kirim diasumsikan sebesar $20 \mathrm{kV}$ dan 400 Volt. Kemudian tegangan terima didapat dari hasil simulasi setelah membuat SLD, memasukkan data-data yang diperoleh dari observasi, dan melakukan running. Adapun rumus yang digunakan untuk menghitung presentase jatuh tegangan pada jaringan yaitu:

$$
\Delta V=\frac{V_{s}-V_{r}}{V_{s}} \times 100 \%
$$

Perhitungan jatuh tegangan pada Bus1:

$$
\begin{aligned}
\Delta V & =\frac{V_{s}-V_{r}}{V_{s}} \times 100 \% \\
& =\frac{150-150}{150} \\
& =0 \%
\end{aligned}
$$

Pehitugan jatuh tegangan pada Bus2:

$$
\begin{aligned}
\Delta V & =\frac{V_{s}-V_{r}}{V_{s}} \times 100 \% \\
& =\frac{20-19,99}{20} \\
& =0,05 \%
\end{aligned}
$$

Dengan menggunakan rumus di atas maka diperoleh hasil presentase jatuh tegangan yang terjadi seperti yang ditampilakan pada tabel 4 .

Tabel 4. Tegangan Hasil Simulasi ETAP Power Station dan Presentase Jatuh Tegangan pada Jaringan Tegangan Menengah Penyulang KLS 06

\begin{tabular}{llcccc}
\hline No & Nama & $\begin{array}{c}\text { Tegangan } \\
(\mathbf{k V})\end{array}$ & $\begin{array}{c}\text { Jatuh } \\
\text { Tegangan } \\
(\mathbf{k V})\end{array}$ & $\begin{array}{c}\text { Tegangan } \\
\text { Setelah Jatuh } \\
\text { Tegangan }(\mathbf{K v})\end{array}$ & $\begin{array}{c}\text { Presentase } \\
\text { Jatuh } \\
\text { Tegangan }(\%)\end{array}$ \\
\hline 1 & Bus1 & 150 & 0 & 150 & 0 \\
2 & Bus2 & 20 & 0,01 & 19,99 & 0,05 \\
3 & Bus3 & 20 & 0,021 & 19,979 & 0,105 \\
4 & Bus4 & 20 & 0,021 & 19,979 & 0,105 \\
5 & Bus6 & 20 & 0,026 & 19,974 & 0,13 \\
6 & Bus8 & 20 & 0,027 & 19,973 & 0,135 \\
7 & Bus9 & 20 & 0,027 & 19,973 & 0,135 \\
8 & Bus11 & 20 & 0,03 & 19,97 & 0,15 \\
9 & Bus13 & 20 & 0,031 & 19,969 & 0,155 \\
10 & Bus14 & 20 & 0,031 & 19,969 & 0,155 \\
11 & Bus16 & 20 & 0,031 & 19,969 & 0,155 \\
12 & Bus17 & 20 & 0,032 & 19,968 & 0,16 \\
13 & Bus20 & 20 & 0,032 & 19,968 & 0,16 \\
14 & Bus23 & 20 & 0,034 & 19,966 & 0,17 \\
15 & Bus25 & 20 & 0,035 & 19,965 & 0,175 \\
16 & Bus26 & 20 & 0,036 & 19,964 & 0,18 \\
17 & Bus27 & 20 & 0,036 & 19,964 & 0,18 \\
18 & Bus28 & 20 & 0,036 & 19,964 & 0,18 \\
19 & Bus29 & 20 & 0,036 & 19,964 & 0,18 \\
20 & Bus30 & 20 & 0,036 & 19,964 & 0,18 \\
\hline & & & & & \\
\hline
\end{tabular}


Berdasarkan tabel di atas, jatuh tegangan tertinggi yang terjadi pada Jaringan Tegangan Menengah KLS 06 yaitu pada Bus27, Bus28, Bus29, dan Bus30. Keempat bus tersebut paling jauh diantara bus-bus lainnya. Hal ini membuktikan bahwa semakin jauh penyaluran energi listrik dari pusat pembangkit mengakibatkan terjadinya jatuh tegangan dan rugi-rugi daya.

Tabel 5. Tegangan Hasil Simulasi ETAP Power Station dan Presentase Jatuh Tegangan pada Jaringan Tegangan Rendah Penyulang KLS 06

\begin{tabular}{|c|c|c|c|c|c|}
\hline No & Nama & $\begin{array}{c}\text { Tegangan } \\
(\mathrm{kV})\end{array}$ & $\begin{array}{c}\text { Jatuh } \\
\text { Tegangan } \\
(\mathbf{k V})\end{array}$ & $\begin{array}{c}\text { Tegangan Setelah } \\
\text { Jatuh Tegangan } \\
\text { (Kv) }\end{array}$ & $\begin{array}{c}\text { Presentase } \\
\text { Jatuh } \\
\text { Tegangan (\%) }\end{array}$ \\
\hline 1 & Bus5 & 0,4 & 0,005 & 0,395 & 1,25 \\
\hline 2 & Bus7 & 0,4 & 0,006 & 0,394 & 1,5 \\
\hline 3 & Bus10 & 0,4 & 0,003 & 0,397 & 0,75 \\
\hline 4 & Bus12 & 0,4 & 0,002 & 0,398 & 0,5 \\
\hline 5 & Bus15 & 0,4 & 0,007 & 0,393 & 1,75 \\
\hline 6 & Bus18 & 0,4 & 0,008 & 0,392 & 2 \\
\hline 7 & Bus19 & 0,4 & 0,002 & 0,398 & 0,5 \\
\hline 8 & Bus21 & 0,4 & 0,004 & 0,396 & 1 \\
\hline 9 & Bus22 & 0,4 & 0,002 & 0,398 & 0,5 \\
\hline 10 & Bus24 & 0,4 & 0,015 & 0,385 & 3,75 \\
\hline 11 & Bus31 & 0,4 & 0,002 & 0,398 & 0,5 \\
\hline 12 & Bus32 & 0,4 & 0,004 & 0,396 & 1 \\
\hline 13 & Bus33 & 0,4 & 0,007 & 0,393 & 1,75 \\
\hline 14 & Bus34 & 0,4 & 0,004 & 0,396 & 1 \\
\hline 15 & Bus35 & 0,4 & 0,007 & 0,393 & 1,75 \\
\hline
\end{tabular}

Tabel 5 menjelaskan bahwa bus yang mengalami jatuh tegangan paling tinggi yaitu Bus24 dengan nilai jatuh tegangan sebesar $3,75 \%$. Sedangkan bus dengan jatuh tegangan paling rendah terjadi pada Bus12, Bus19, Bus22 dan Bus31 sebesar 0,5\%.

Menurut SPLN 72: 1987 batas maksimum drop tegangan yang diijinkan pada Jaringan Tegangan Menengah yaitu 5\% dan pada jaringan Tegangan Rendah batas yang diijinkan yaitu 4\%. Jika melebihi dari batas tersebut maka perlu dilakukan perbaikan tegangan.

Dari hasil yang diperoleh pada Tabel 4 diketahui bahwa pada Jaringan Tegangan Menengah di Penyulang KLS 06 terjadi jatuh tegangan akan tetapi masih dalam kondisi aman. Jatuh tegangan yang terjadi masih jauh dari batas makismal yang diijinkan. Sedangkan tabel 5 menunjukkan profil tegangan pada Jaringan Tegangan Rendah. Dari tebel tersebut diketahui ada jatuh tegangan pada bus yang mendekati batas yang diijinkan yaitu pada Bus24. Jatuh tegangan yang terjadi pada bus ini sebesar 3,75\%. Bus24 merupakan jaringan dengan tegangan rendah yang memiliki batas maksimal jatuh tegangan yang diijinkan sebesar 4\%. Salah satu penyebab dari besarnya nilai jatuh tegangan yang terjadi yaitu karena besarnya beban yang harus disuplai oleh trafo.

Menurut Narottama et al. (2014: 126), pembebanan ideal pada transformator distribusi yaitu $<80 \%$. Sedangkan pada Tabel IV, trafo dengan nomor gardu KLS06-110 menunjukkan beban yang harus disuplai yaitu sebesar $93,4 \%$ dari kapasitasnya. Sehingga pembebanan pada trafo tersebut dapat dikatakan melebihi bata standar. Dampak yang diberikan akibat beban 
berlebih pada trafo selain jatuh tegangan yaitu kerusakan trafo tersebut.

Ditinjau dari jumlah pelanggan PLN tiap tahunnya yang megalami peningkatan, untuk mempertahankan kualitas tegangan yang diterima oleh pelanggan agar tetap baik perlu dilakukan perencanaan ulang. Upaya ini dilakukan agar beban pada setiap trafo tidak mengalami overload. Salah satu cara untuk memperkecil nilai jatuh tegangan yaitu dengan memasang transformator sisip.

Jika dilihat dari tabel $\mathrm{V}$ dan VI jatuh tegangan tertinggi terjadi pada Bus24 besarnya jatuh tegangan tersebut hampir mencapai batas yang diijinkan. Maka untuk memperbaiki kualitas tegangan pada Bus24 sebagai upaya antisipasi ketika ada penambahan beban pada waktu kedepannya dan agar tidak terjadi beban lebih, upaya yang harus dilakukan yaitu dengan sisip trafo yang diparalel dengan trafo KLS06110 ke trafo baru yang disisipkan. Sisip trafo dilakukan dengan pemasangan trafo baru di gardu yang sudah ada. Berikut ini adalah datadata trafo yang disisipkan untuk memperbaiki kualitas tegangan pada jaringan:

$\begin{array}{ll}\text { Daya } & : 50 \mathrm{kVA} \\ \text { Tegangan Primer } & : 20 \mathrm{kV} \\ \text { Tegangan Sekunder } & : 400 \mathrm{~V} \\ \text { Frekuensi } & : 50 \mathrm{~Hz} \\ \text { Trafo } & : 3 \text { phasa }\end{array}$

Gambar 5 merupakan hasil simulasi setelah dilakukan pemasangan transformator sisip.

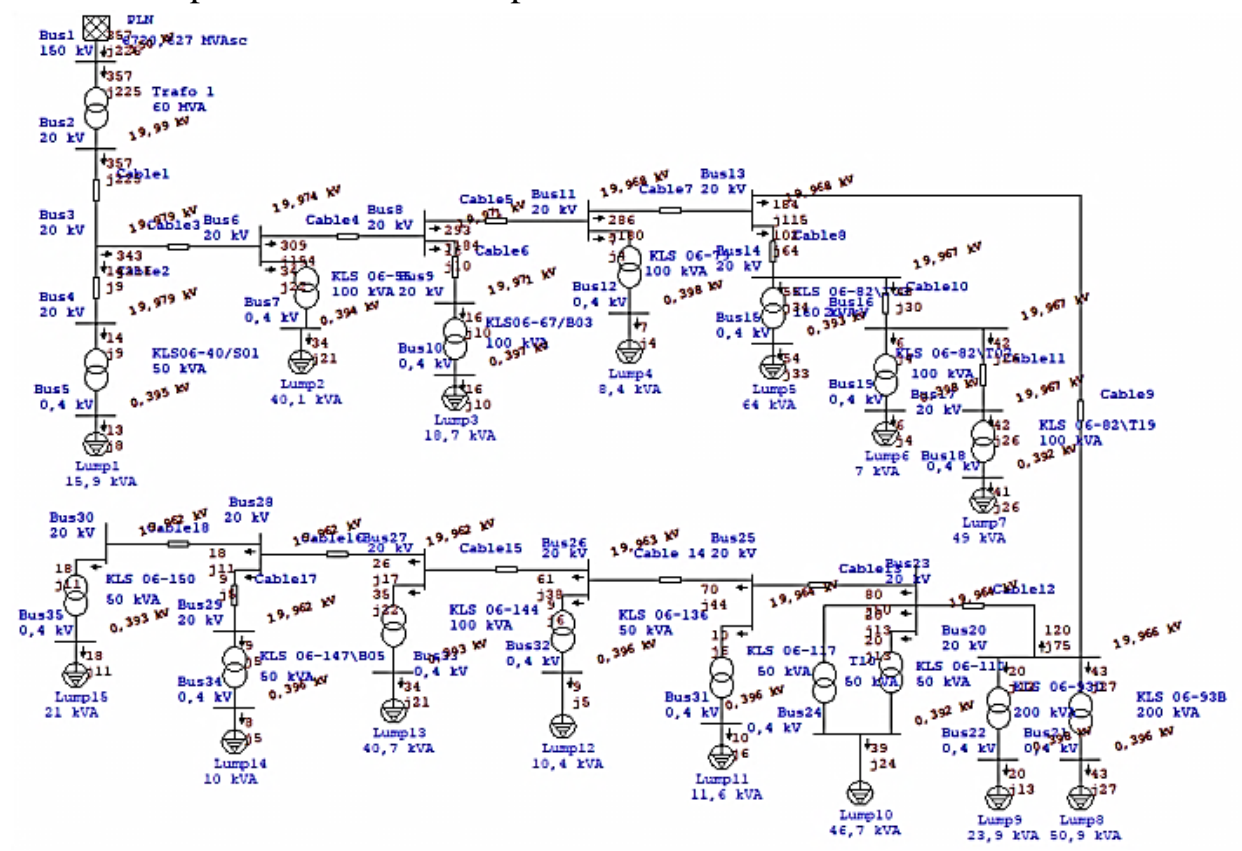

Gambar 5. Single Line Diagram Perbaikan Jatuh Tegangan Menggunakan ETAP Power Station

Dari Tabel 6 dan 7 diketahui terjadi perubahan presentase jatuh tegangan ketika sebelum dan sesusah dilakukan sisip transformator. Sebelum dilakukan perbaikan, tegangan pada Bus24 sebesar 0,385 kV sedangkan setelah perbaikan tegangan berubah menjadi 0,392. Dari yang sebelumnya memiliki presentase jatuh tegangan sebesar $5 \%$ kemudian setelah dilakukan sisip trafo dengan kapasitas $50 \mathrm{kVA}$ didapat presentase jatuh tegangan sebesar 2\%. Tegangan ujung pada Bus24 menjadi lebih baik kualitasnya.

Perbandingan hasil simulasi jatuh tegangan yang terjadi pada jaringan distribusi penyulang Kalisari 06 sebelum dan sesudah dilakukan perbaikan dapat dilihat pada gambar 6 dan 7. 
Tabel 6 Perbedaan Jatuh Tegangan Sebelum dan Sesudah Perbaikan pada JTM

\begin{tabular}{|c|c|c|c|c|}
\hline \multirow[t]{2}{*}{ No } & \multirow[t]{2}{*}{ Nama } & \multicolumn{2}{|c|}{ Jatuh Tegangan } & \multirow{2}{*}{$\begin{array}{c}\text { Selisih } \\
(\%)\end{array}$} \\
\hline & & $\begin{array}{c}\text { Sebelum } \\
(\%)\end{array}$ & $\begin{array}{c}\text { Sesudah } \\
(\%)\end{array}$ & \\
\hline 1 & Bus1 & 0 & 0 & 0 \\
\hline 2 & Bus2 & 0,05 & 0,05 & 0 \\
\hline 3 & Bus3 & 0,105 & 0,105 & 0 \\
\hline 4 & Bus4 & 0,105 & 0,105 & 0 \\
\hline 5 & Bus6 & 0,13 & 0,13 & 0 \\
\hline 6 & Bus8 & 0,135 & 0,145 & $-0,01$ \\
\hline 7 & Bus9 & 0,135 & 0,145 & $-0,01$ \\
\hline 8 & Bus11 & 0,15 & 0,16 & $-0,01$ \\
\hline 9 & Bus13 & 0,155 & 0,16 & $-0,005$ \\
\hline 10 & Bus14 & 0,155 & 0,165 & $-0,01$ \\
\hline 11 & Bus16 & 0,155 & 0,165 & $-0,01$ \\
\hline 12 & Bus17 & 0,16 & 0,165 & $-0,005$ \\
\hline 13 & Bus20 & 0,16 & 0,17 & $-0,01$ \\
\hline 14 & Bus23 & 0,17 & 0,18 & $-0,01$ \\
\hline 15 & Bus25 & 0,175 & 0,18 & $-0,005$ \\
\hline 16 & Bus26 & 0,18 & 0,185 & $-0,005$ \\
\hline 17 & Bus27 & 0,18 & 0,19 & $-0,01$ \\
\hline 18 & Bus28 & 0,18 & 0,19 & $-0,01$ \\
\hline 19 & Bus29 & 0,18 & 0,19 & $-0,01$ \\
\hline 20 & Bus30 & 0,18 & 0,19 & $-0,01$ \\
\hline
\end{tabular}

Tabel 7 Perbedaan Jatuh Tegangan Sebelum dan Sesudah Perbaikan pada JTR

\begin{tabular}{ccccc}
\hline No & Nama & \multicolumn{2}{c}{ Jatuh Tegangan } & Selisih \\
\cline { 3 - 4 } & & $\begin{array}{c}\text { Sebelum } \\
(\boldsymbol{\%})\end{array}$ & $\begin{array}{c}\text { Sesudah } \\
(\boldsymbol{\%})\end{array}$ & \\
\hline 1 & Bus5 & 1,25 & 1,25 & 0 \\
\hline 2 & Bus7 & 1,5 & 1,5 & 0 \\
\hline 3 & Bus10 & 0,75 & 0,75 & 0 \\
\hline 4 & Bus12 & 0,5 & 0,5 & 0 \\
\hline 5 & Bus15 & 1,75 & 1,75 & 0 \\
\hline 6 & Bus18 & 2 & 2 & 0 \\
\hline 7 & Bus19 & 0,5 & 0,5 & 0 \\
\hline 8 & Bus21 & 1 & 1 & 0 \\
\hline 9 & Bus22 & 0,5 & 0,5 & 0 \\
\hline 10 & Bus24 & 3,75 & 2 & 1,75 \\
\hline 11 & Bus31 & 0,5 & 1 & $-0,5$ \\
\hline 12 & Bus32 & 1 & 1 & 0 \\
\hline 13 & Bus33 & 1,75 & 1,75 & 0 \\
\hline 14 & Bus34 & 1 & 1 & 0 \\
\hline 15 & Bus35 & 1,75 & 1,75 & 0 \\
\hline
\end{tabular}

Perbandingan Jatuh Tegangan Sebelum dan Sesudah

Perbaikan pada JTM

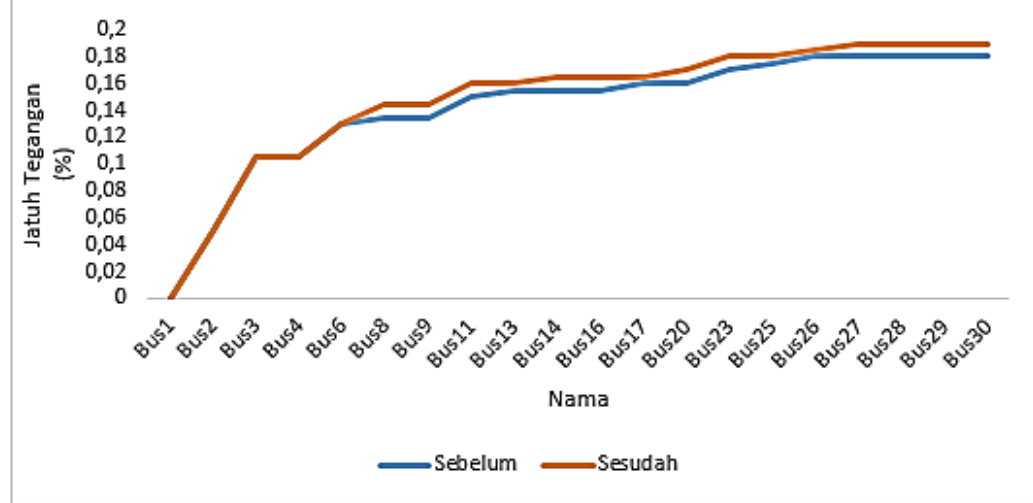

Gambar 6. Grafik Perbandingan Jatuh Tegangan Sebelum dan Sesudah Perbaikan pada JTM 


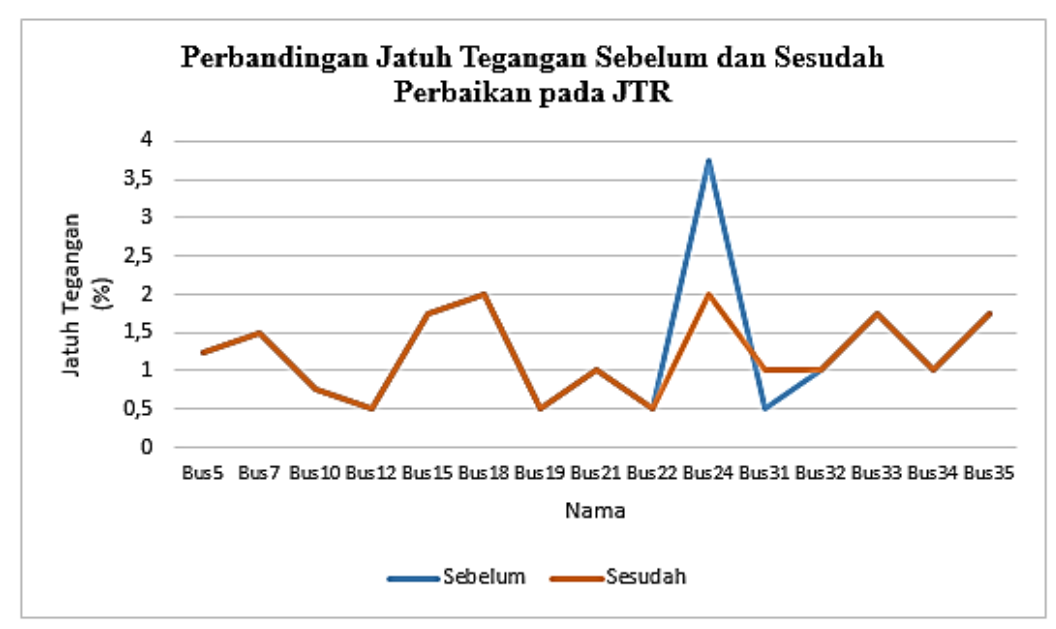

Gambar 7. Grafik Perbandingan Jatuh Tegangan Sebelum dan Sesudah Perbaikan pada JTR

Hasil perhitungan jatuh tegangan pada penyulang Kalisari 06 menggunakan software ETAP Power Station 12.6.0 menunjukkan kondisi jaringan masih sesuai standar. Akan tetapi pembebanan pada salah satu transformator melebihi batas yang ideal sehingga jatuh teganagan yang terjadi pada transformator tersebut lebih besar dan mendekati batas yang diijinkan.

Pada Bus24, terjadi jatuh tegangan sebesar 3,75\%. Menurut SPLN 72: 1987 batas maksimal jatuh tegangan pada JTR yaitu $4 \%$. Besar jatuh tegangan yang terjadi pada Bus24 masih dalam kategori standar. Akan tetapi untuk mengantisipasi terjadinya beban berlebih pada transformator KLS06-110 akibat bertambahnya jumlah pelanggan PLN yang memungkinkan terjadinya penambahan beban pada transformator tersebut, dilakukanlah perencanaan sisip transformator sehingga beban disuplai oleh dua transformator. Dengan penyisipan tersebut, didapat nilai jatuh tegangan pada Bus24 sebesar 2\%. Nilai ini lebih kecil $1,75 \%$ daripada sebelum dilakukan sisip transformator. Dengan penyisipan transformator T10 juga mempengaruhi jatuh tegangan pada beberapa bus lainnya.

\section{SIMPULAN}

Berdasarkan paparan pembahasan di atas dapat ditarik kesimpulan bahwa besar jatuh tegangan pada jaringan Penyulang Kalisari 06 masih dalam standar yang diizinkan sesuai SPLN 72: 1987. Jatuh tegangan terbesar terjadi pada Bus24 dengan nilai 3,75\% mendekati batas maksimal yang diijinkan. Selanjutnya, Solusi yang digunakan untuk meminimalkan jatuh tegangan yang terjadi yaitu dengan melakukan sisip trafo distribusi 3 fasa $50 \mathrm{kVA}$ dikarenakan beban pada trafo distribusi tersebut sudah melebihi batas pembebanan yang diijinkan. Hasil dari simulasi dengan menambahkan trafo menjadikan jatuh tegangan pada Bus 24 berkurang menjadi $2 \%$.

\section{DAFTAR RUJUKAN}

Daryanto. 2002. Pengetahuan Teknik Listrik. Jakarta: PT Bumi Aksara.

Hayusman, L. M., T. Hidayat, C. Saleh, I. M. Wartana dan T. Herbasuki. 2017. Pelatihan Software ETAP ( Electrical Transient Analyzer Program. Industri Inovatif . 7(1): 7-11.

Martinez-Molina, M. A., S. N. Ladezma. 2016. Analysis of three-phase load flow problem in distribution networks with the inclusion of symmetric and asymmetric transformer connections. IEEE

Multa, L. dan R. P. Aridani. 2013. Modul Pelatihan ETAP. Yogyakarta: Magatrika.

Narottama, A. A. N. M., I. G. A. M. Sunaya, I. M. Purbhawa dan K. R. D. Noviyanti. 2014. Analisis Pengaruh Rekonfigurasi Jaringan Terhadap Pembebanan 
Transformator Pada Gardu Distribusi Ka 1316 Penyulang Sriwijaya. JURNAL MATRIX 4(3): 125-130.

Salman, R. 2017. Analisis Penempatan Transformator Distribusi Berdasarkan Jatuh Tegangan. JITEKH 6(1): 17-21.

SPLN 72-1987. Spesifikasi Desain untuk Jaringan Tegangan Menengah (JTM) dan Jaringan Tegangan Rendah (JTR). Departemen Pertambangan dan Energi Perusahaan Umum Listrik Negara. Jakarta
SPLN 64-1985. Petunjuk Pemilihan dan Peenggunaan Pelebur pada Sistem Distribusi Tegangan Menengah. Departemen Pertambangan dan Energi Perusahaan Umum Listrik Negara. Jakarta

Tanjung, A. 2014. Rekonfigurasi Sistem Distribusi $20 \mathrm{KV}$ Gardu Induk Teluk Lembu dan PLTMG Langgam Power Untuk Mengurangi Rugi Daya dan Drop Tegangan. Sains, Teknologi, dan Industri 11(2): 160-166. 